\title{
The Economy of Shark Conservation in the Northeast Pacific: The Role of Ecotourism and Citizen Science
}

\author{
Peter A. Mieras ${ }^{*, 1}$, Chris Harvey-Clark ${ }^{\dagger}$, Michael Bear $^{\ddagger}$, Gina Hodgin $^{\S}$, \\ Boone Hodgin ${ }^{\S}$ \\ *Rendezvous Dive Adventures, Port Alberni, BC, Canada \\ ${ }^{\dagger}$ Dalhousie University Faculty of Agriculture, Truro, NS, Canada \\ ${ }^{\ddagger}$ Ocean Sanctuaries, San Diego, CA, United States \\ ${ }^{\S}$ Ravencroft Lodge, Valdez, AK, United States \\ ${ }^{1}$ Corresponding author: e-mail address: peter@rendezvousdiving.com
}

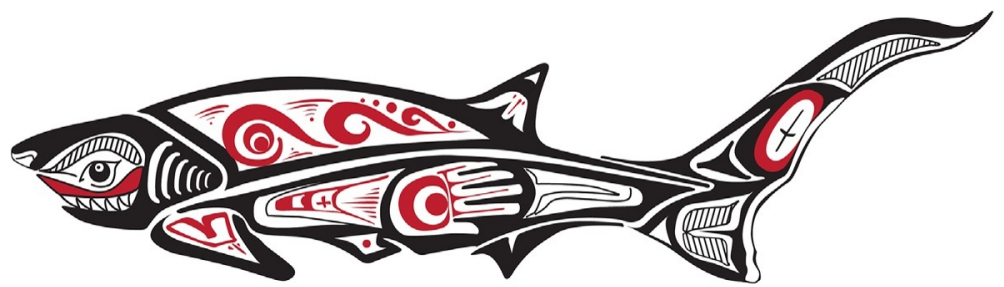

First Nation image of a six gill shark. Courtesy: Artist: Kelly Foxcroft-poirier.

\section{Contents}

1. Introduction

2. Development of Shark-Based Ecotourism in the NEP 82

2.1 Recreational Fisheries for Sharks 83

$\begin{array}{ll}2.2 \text { Shark Encounters } & 85\end{array}$

2.3 Citizen Science 98

$\begin{array}{ll}2.4 \text { Case Studies } & 100\end{array}$

3. Conclusion 107

References 108

\section{Abstract}

Historically sharks have been seen either as a source of income through harvesting, or as a nuisance and danger. The economic value of sharks has traditionally been measured as the total value of sharks caught for liver oil, fins, or meat for consumption. Sharks have also been killed to near extinction in cases where they were seen as a threat to fisheries 
on other species. This is illustrated by the mass extermination of Basking Sharks (Cetorhinus maximus) in British Columbia. They were seen as a nuisance to fishermen as they got entangled in gill nets during the salmon fishing season. However with the development of the SCUBA diving industry, and ecotourism in general, increased awareness of the role sharks play in marine ecosystems has resulted in changes in how they are perceived and utilized. Despite an ongoing harvest of sharks such as the North Pacific Spiny Dogfish (Squalus suckleyi), sharks now generate economic value through SCUBA diving enthusiasts who travel the globe to see, swim with, and photograph them. The use of digital cameras and other digital media has brought sharks into households around the world and increased awareness of the conservation issues facing many species. This renewed appreciation has led to a better understanding of sharks by the public, resulting in advocates calling for better protections and conservation. In particular, a growing part of the SCUBA diving community wants to contribute to conservation and research projects, which has led to participation in citizen science projects. These projects provide scientific data but also gain ground as ecotourism activities, thus adding to both economic value of tourism and conservation efforts.

\section{INTRODUCTION}

Historically in the eyes of the indigenous peoples on the shores of the Northeast Pacific Ocean (NEP), sharks and other elasmobranchs have been seen as sources of food and inspiration. The spotted ratfish (Hydrolagus colliei) was a regular part of meals and their teeth have often been found in archaeological digs of First Nation midden heaps in the NEP region. Other species such as the North Pacific Spiny Dogfish (Squalus suckleyi) are still harvested by commercial fisheries, albeit at levels well below historical highs. In the spiritual perception of the First Nations on the coast most animals were seen as part of a spirit world and believed to have special powers. For example, the Haida attach great spiritual powers to the "dogfish woman" and the Tlingit also used the shark as a clan name (Wooshkeetaan).

When European settlers came to the region, they brought with them a simplified view of sharks. For them, sharks were only a natural resource to be used for oil, skin, etc. The perception was that all sharks were evil regardless of species and they were described as "mortal enemies of seamen". This stigma was expressed as late as the 1956 Jacques Cousteau movie "The silent world". This movie started a worldwide interest in underwater exploration and in later documentaries the shark's bad reputation slowly disappeared. However, the 1975 movie "Jaws" rekindled the skewed idea of sharks being mindless monsters that will attack anyone and anything in the water. 
A worldwide hunt followed the movie "Jaws" and millions of sharks were needlessly culled, including specimens of many species that were completely harmless to man. This was of course not an event unique to the NEP and most of these culling efforts took place in tropical waters. However, it did cement the perception of sharks as dangerous and mindless killers in the mind of many members of the general public. In a more recent open letter sent to Columbia Pictures for the release of the movie "The Shallows" touted as "Jaws for the next generation", a number of marine science researchers asked for a $2 \%$ profit share to be donated to the National Fish and Wildlife fund. In this letter they acknowledge the direct link between the movie "Jaws" and the popularization of recreational shark culling. This sometimes called "Jaws effect" was even cited as the basis for a shark culling policy in Western Australia (Neff, 2014).

In the 1950s, around the time that Cousteau's "The Silent World" came out, Basking Sharks (Cetorhinus maximus) in British Columbia and Washington State were killed to the point of near extirpation, and for all intents and purposes the species can now be considered virtually extinct in British Columbia (http://www.dfo-mpo.gc.ca/species-especes/profiles-profils/ basking-pelerin-eng.html). Internationally, the International Union for Conservation of Nature (IUCN) Red List assessment has categorized Basking Sharks as Vulnerable globally and Endangered in the northeast Atlantic Ocean and the NEP, and even Critically Endangered in the case of Barkley Sound, BC. This mass killing stemmed from the idea that these planktoneating giants were a nuisance to local gillnet fisheries as they sometimes became entangled in the nets. They were also identified (incorrectly) as "salmon-killing monsters" (Victoria Columnist, September 9, 1955). Thus the solution was to put huge steel blades on the bow of the Department of Fisheries patrol boats and ram Basking Sharks at the surface, thus cutting them into pieces and leaving them to die.

In the late 1980s and the early 1990s a test fishery on Bluntnose Sixgill Sharks (Hexanchus griseus) was initiated. Marketed as "snow shark" this subsidized fishery was started to give the depleted salmon fishery an alternative source of income, even though the species was considered data deficient at the time. The fishery was unsuccessful and was abandoned when government subsidies ended. The mere fact that a species was simply offered as a band-aid for a deteriorated salmon fishery confirms the thought that, other than economic harvest value, no consideration to this shark in a wider ecological or economical context was given. As the SCUBA diving industry saw a boom of Sixgill Shark sightings in the 1980s and 1990s, more and more 
divers became aware that the sharks they encountered were not the mindless monsters portrayed in the media or movies and a new revenue source developed. Sixgill Sharks in Barkley Sound and around Hornby Island attracted more and more divers wanting to swim with these mysterious deep-sea creatures. As divers started to spread the stories of their encounters, a wider review of the sharks' reputation slowly came about and, with time and research that showed the importance of sharks within a healthy ecosystem, regional opinions shifted. The result was that the general public started to pay attention to the demands of activists that wanted to protect sharks in their local area.

At the same time documentaries and TV programs alternately showing the destructive practices of shark finning and the beauty of sharks in their natural habitat started to fuel a popular worldwide movement that wanted shark finning ended and banned. Eventually the Asian communities in the Pacific Northwest came under increasing pressure to abandon shark fin soup and importing any shark-related products. Some initiatives such as "Shark Truth" (http://www.sharktruth.com), a project designed to raise awareness of the wasteful use of sharks and to stop the consumption of shark fin soup, came out of the Asian community itself. One can say that the current view on sharks has changed dramatically over the last three decades and this has some important and positive effects on both sharks and the economy.

In this post "Jaws" era, sharks and their kin have metamorphosed in the public eye, transfigured from monsters of the deep to becoming, in the past 20 years, a major ecotourism draw to many regions (Gallagher and Hammerschlag, 2011). In the early 1990s, some proposed sharks in their natural environment could be worth millions of dollars, in the form of added economic value as living resources in attracting ecotourists, much as the presence of large game mammals attracts tourists to the savannas of Africa. This has in turn led to one of the most difficult metrics to quantify: the economic value in conserving large charismatic species, both terrestrial and marine, as an ecotourism resource, particularly as we enter the carbon neutral age. Ehrlich and Ehrlich (1981) recognized the cultural value of unadulterated wilderness and species left alone in their native ecosystems as one of four categories of "ecosystem services" and noted the extra challenge of measuring economic indices of this particular intangible. The public appreciation of ecosystem services is currently focused on the costs to offset the net depletion of the planet's atmosphere by anthropogenic greenhouse gases. Carbon dioxide sequestration and conversion performed by living entities, 
from old growth forests to unmolested coral reefs, are reflected in the concept of the carbon credits these entities provide. Hence, the net ecosystem value of living entities is currently focused through the lens of their role as carbon converters and in carbon sequestration. In turn this concept is being used in first world economies to leverage increased taxation on citizens, to continue to licence unsustainable industrial activities based on carbon offsets, and to allow private corporations to charge customers downstream additionally for carbon offsets, resulting in some cases in windfall profits (Murell, 2008). Already deeply embedded in a carbon-based economy, with a lack of clear disclosure or transparency of the subsequent allocation of these revenues to make actual inroads in carbon depletion and global warming, taxpayers should be asking one question in this shell game: Where is the money, and what proof exists that it is actually being disbursed to further reduce carbon in the Earth's atmosphere?

From the global realpolitik of carbon taxation to the world of shark ecotourism and conservation is not such a long leap, as shark ecotourism has also become a "where is the money" issue. Many authors have pointed out the rapid decrease in wild spaces and diminishing species on the planet, the loss of habitat, and human technological advances that have allowed once flourishing assemblages of animals, from plains bison to migratory schools of giant bluefin tuna, to be hunted to near extinction (Diamond, 1999; Safina, 1998). This points out a second challenge: in an era when shark fins can sell in excess of 225 USD per kilogram, applying a cultural economic value to sharks is a double-edged sword. Are they more valuable alive or dead?

Using economic indices to determine human moral concern for conservation of species is a slippery slope. The crux of the challenge is to balance several things: first, the economic value of a species and the consequences of conservation on economic interests; second, the ecologic service value of that species in supporting and preserving the diversity of the biosphere; and third, the intangible cultural value of the species. Cultural value is an emotionally driven, human-based valuation. It is also not universally held, but in hierarchical terms is a luxury of first world economies, where food, shelter, health, and safety are more or less a given. Experiencing and conserving nature in an untamed, unadulterated form, on land and sea, as close to its unaffected natural state as is possible, should be a universal privilege but sadly, it is not. Over large portions of the planet's oceans this experience is no longer achievable given massive declines primarily due to overharvest and other anthropogenic stressors (Myers and Worm, 2003). 


\section{DEVELOPMENT OF SHARK-BASED ECOTOURISM IN THE NEP}

On a worldwide scale the economic impact of shark tourism continues to grow and may exceed the economic value of commercially landed sharks in the next decade. Some operations have seen their customer numbers and revenue for underwater shark encounters increase more than eightfold in 12 years, 1999-2010 (Gallagher and Hammerschlag, 2011). It is very hard to get an exact number of the global economic impact of sharkdirected encounters, but a 2013 study suggested a global estimate of 590,000 shark watchers (defined as observing from boats, or while snorkelling or diving) with a direct revenue of $>341$ million USD annually (CisnerosMontemayor et al., 2013). This economic value comes from direct revenues such as snorkelling, diving, and fishing tours and associated employment, but there are also significant indirect value making the impact potentially much larger, such as the costs associated with travel, accommodation, and food.

What is certain is that the economic impact of shark-driven ecotourism in the NEP is small when taken as a percentage of the global shark ecotourism industry. Factors that impact this are mainly the water clarity and ease of actually finding the sharks in relatively cold and dark NEP waters. In Alaska, British Columbia, and Washington State the species of sharks that can be sought out and seen are mainly the Sixgill Shark and Salmon Shark (Lamna ditropis). The Salmon Shark is notoriously shy and seasonally dependent on salmon (Oncorhynchus spp.) runs and Walleye Pollock (Gadus chalcogrammus). The Sixgill Shark is also a seasonal visitor to depths accessible by SCUBA, but even less is known about where and why they are present. In Oregon there does not seem to be any shark-directed ecotourism, though some pelagic species are encountered as bycatch during tuna fisheries and considered a welcome diversion by some anglers. Further south in California the warmer climate, increased water clarity and more reliable shark sightings contribute to a larger part of the in-water shark ecotourism taking place. There Shortfin Mako Sharks (Isurus oxyrinchus), Blue Sharks (Prionace glauca), and Great White Sharks (Carcharodon carcharias) are lured to the divers with bait or decoys. However, inclement weather and annual variation in number of sharks sighted still make it a somewhat "hit or miss" activity. If one compares this to sites like Guadalupe Island, Mexico, or those in and around the Bahamas and other reliable sighting areas, it is easy to understand the lesser importance of the NEP shark ecotourism sector. Tourists spend considerable 
amounts of money on getting to a shark-sighting area and want to have the highest chances of actually seeing the animals.

Shark-based tourism can be separated into three main activities: recreational fishing, shark sightings from the surface, and underwater encounters. One can argue that media and film crews who film sharks, and spend large sums of money to get exclusive access to a dive area, contribute to the total value of the shark-sighting economics. However, often these contributions are incidental in nature and are therefore not taken into account in this overview.

On a worldwide scale, as well as on a local scale, a number of people participating in ecotourism activities to view live sharks are hard to quantify given incomplete or nonexistent numbers by operators, governments, and fisheries departments. Thus we do not know the actual numbers of people involved and their effect on shark conservation, but we can document specific trends in shark ecotourism as described later.

\subsection{Recreational Fisheries for Sharks}

Given the current minimal economic factor of recreational shark fishing in the NEP, we can take this to be an insignificant economic contributor on a global scale. However, there may be a significant impact for local operators, stores, and associated services like accommodations, restaurants, and travel.

As far as trends go, shark-directed recreational fishing trips vary from year to year and are dependent on factors such as available income and general economic trends, and possibly on shark abundance. One trend in the NEP is the lower number of sharks harvested and the increased number of sharks caught and released. Since 2010 few sharks or rays have been reported as harvested by recreational fishers (NOAA report on the Fisheries Economics of the United States). This may be due to a shift in perception and attitudes towards sharks and increased education about sharks' importance as part of a healthy ecosystem. Alternatively, in some cases, it is simply a matter of decreased abundance of the sharks, such as in Alaska where the recreational fishery on Salmon Sharks disappeared due to decreased overall abundance potentially from the fishing pressure itself.

Fig. 1 shows the collective numbers of sharks reported in fisheries off Alaska, Washington, Oregon, and California. There are no known sharkdirected recreational fisheries in British Columbia, though North Pacific Spiny Dogfish may be retained as bycatch during salmon and bottomfish fishing. The exception to the pattern of reduced overall encounters was 
Pacific Northeast recreational shark fishing (AL, WA, OR, and CA)

\begin{tabular}{|l|l|l|l|l|l|l|l}
\hline \multicolumn{2}{l}{ Sharks and rays caught (in thousands of fish) } \\
\hline Year & 2008 & 2009 & 2010 & 2011 & 2012 & 2013 & 2014 \\
\hline Harvested & $1^{\mathrm{a}}$ & $1^{\mathrm{a}}$ & 0 & 0 & 0 & 0 & 0 \\
\hline Released & 12 & 10 & 3 & 1 & 3 & 2 & 4 \\
\hline
\end{tabular}

an this table "1" means 1000-1499 fish.

Source: NOAA Fisheries Economics of the United States 2014 report.

Fig. 1 NOAA fisheries report of numbers of sharks caught in the NEP.

in Washington State where 4000 shark or rays were reportedly released in the recreational fisheries category. The 4000 sharks released in 2014 represent $0.11 \%$ of the total number of reported fish caught. If we project this percentage in Washington State based on the number of fishing industry jobs (6180), the income generated (287,917,000 USD), and the total of sales and durable good expenditures $(1,328,913,000$ USD) presented in the report, the shark-related economic impact is 6.8 jobs, 316,709 USD in income, and 1,416,804 USD in sales and durable expenditures.

Even these numbers do not represent the complete picture since the reporting method did not include sharks as a "key species". However, it is well documented that Salmon Sharks were the subject of an intense recreational fishery in Alaska between 2001 and 2011 (Tribuzio et al., 2014). Recreational fishermen were allowed to catch one Salmon Shark per day with a maximum of two per year. In Oregon some fishing charter operators offer Blue Shark fishing trips. However, the economic impacts of these seem to be too low to show in any fisheries reports or may not be reported at the federal level (i.e., to NOAA Fisheries). Some shark landings have been reported to the Alaskan Department of Fish and Game (ADFG) but were apparently not included in the Fisheries Economics of the United States reports.

All recreational shark-directed fisheries in the NEP, except those for North Pacific Spiny Dogfish in Washington State, advise a "catch and release" policy, but it is up to the discretion of the customer whether the sharks are actually released or harvested. Even if sharks are released, it can be surmised that there is a certain degree of mortality due to fishing-related injuries. This rate may be $15 \%$ or higher based on figures for the year 2000 , that suggest of the 227,000 metric tons of sharks released alive 34,000 metric tons die postrelease and 193,000 metric tons survive (Myers and Worm, 2003). The North Pacific Fisheries Management Council assumes a 100\% mortality rate in sharks caught and released. The fact that this "catch and 
release" option is offered and promoted means that there is some awareness of the potential negative view on shark fishing and maybe even of the value of the sharks being alive. Although this may not be labelled a conservation effort, it might have a positive impact on the shark's survival and, thus, its population.

\subsection{Shark Encounters}

In the early 1970s as the SCUBA diving industry started growing, both on a worldwide scale and in the NEP, many divers started travelling and looking for exiting wild animal encounters. This included shark encounters. Although most of the shark encounters originated, and continue to take place, in tropical regions where clear waters and a higher abundance and biodiversity of sharks make it easier to see them during a dive, the NEP saw its own shark tourism develop. In the 1975 October issue of Pacific Diver magazine a shark-specific article mentions sharks of British Columbia (BC), and the issues of September 1981 and April/May 1985 of Diver magazine specifically mention Hornby Island and Tyler Rock in Barkley Sound as destinations for diving with Sixgill Sharks.

The initial discovery of Sixgill Sharks at Hornby Island is credited to Bruce Howe, a friend of the Zielinski family, owners of the dive operation in Ford Cove. In the early 1970s, he was diving on Flora Islet when he saw sharks. In subsequent dives, it was confirmed that they were indeed Bluntnose Sixgill Sharks. The news of this novelty spread in the diving community, and in the late 1970s and throughout the 1980s, shark charters started to take off both on Hornby Island and in Barkley Sound on the West coast of Vancouver Island where Sixgill Sharks were often seen at Tyler Rock. Biologist and underwater cameraman Neil McDaniel visited both sites and started to collect sighting data on the sharks in both areas. Hornby Island grew into a destination to see these sharks, and in the 1980s the dive charter had between 800 and 1000 "diver guest days" (defined as a day during which a group of divers specifically seeks out sharks). If we assume a minimum of eight divers per day at 25 Canadian dollars per guest, the direct economic impact would be a minimum of over 180,000 Canadian dollars (price source: Diver Magazine ad). This was important ecotourism income for the charter operator but also for other businesses in the immediate area. In addition to the divers coming from all over the world, film crews and researchers were additional contributors to this "shark ecotourism boom". This estimate does not take into account the numerous live-aboard vessels 
that stopped in the area to have their customers dive with the sharks, though participation via this method was uncommon. Although Rendezvous Dive Ventures (currently named Rendezvous Dive Adventures) had increased ecotourism visitor numbers from the Sixgill Sharks seen by divers in Barkley Sound, the direct impact on their revenue stream was not as large as the one on Hornby Island.

In the late 1990s, researchers, Malcolm Ramsay and Robert Dunbrack, started systematic data collection of the sharks near Hornby Island and installed a video system at Flora Islet (near Hornby Island) that allowed them to obtain identification of individual sharks and monitor their presence, and also collect data such as length and sex. These video observation served as a tool for local population assessment of the Sixgill Sharks and they successfully identified 70-100 individuals in the year of the highest abundance (Dunbrack, 2008). Images and sightings from diving clients were also used to compare sharks and complete the database.

The encounters at Hornby Island were set up as completely natural encounters, which meant low impact to the sharks. The lack of baiting or chumming to attract sharks, and the restriction of dive time due to the deeper waters, served to further minimize this impact. The choice not to bait for the sharks was made with the long-term health of the sharks and sustainability of the business model in mind; however, anthropogenic impacts on the sharks still occurred. Despite the fact that there was no commercial shark fishery around Hornby Island, it was a known practice of long line fisherman in the area to keep the sharks and sell or use the meat for bait in prawn traps. As the firm shark meat kept longer in the traps, it was a sought after commodity. Another impact was bycatch of the sharks and, although they were typically released, many sharks suffered significant injuries and deformities to their mouths and were seem swimming with hooks and lines still lodged in their mouths. In 1996 and 1997 the number of sharks slowly began to diminish and in 2005 a sudden population crash occurred (Dunbrack, 2008). The decrease in shark sightings caused a corresponding drop in shark dive tourism and overall revenue. After 2005 shark sightings became so sparse that many divers did not bother to try to dive with the sharks. Fortunately Hornby Island diving was able to adjust their business model to other underwater attractions and is still a thriving diving operator.

At the same time the Sixgill Shark dives in Barkley Sound continued, but to a lesser degree. The impact of a test fishery for this "underutilized" species was thought to have had a profound effect on the number of sightings. The fishery was started without data on critical life history parameters, such as age 
at maturity and reproductive and recruitment rates, and without a thorough population assessment. As a result, the local abundance of sharks declined during the test fishery and did not show any signs of recovery even after it ended.

Two other operations in British Columbia, Canada near the Campbell River and in the Strait of Georgia region have historically offered shark feeding dives with North Pacific Spiny Dogfish near the wharf of popular fishing lodges. Divers have hand-fed fish heads to dogfish at this site and occasionally to marauding seals as well, for several decades. In recent years the number of North Pacific Spiny Dogfish seen at this site has significantly diminished, from thousands seen at one time in the 1970-1990s to a dozen individuals in recent years.

In California a number of operators offer shark trips with observations from the surface. They combine these trips mostly with cage dives for Great White Sharks in the Greater Farallones National Marine Sanctuary (GFNMS). Depending on the operator, groups can range from as little as four to a maximum of six surface observers and the average cost for a surface observer day trip is around 450 USD per person. In an attempt to gauge the actual direct revenues from these trips, it became clear that some operators did not want to divulge the exact numbers of topside observers and divers they took out. However a quick calculation based on the prices and schedules stated on their websites suggests that the potential direct revenue could be as high as 120,000 USD annually. The actual number of bookings seems to be much lower as large parts of the schedule advertised seem completely open at any moment. Compared to the number of underwater encounters, surface encounters are a small contributor to the economic value of shark ecotourism in the NEP.

In Northern California, there are two main operators who advertise and run shark encounters under nine different company names. The majority of their activity is diving with Great White Sharks in cages at the GFNMS. Operators working at the GFNMS need a permit. In recent years, there have been four permit holders, two of which are purely surface sighting operations and two offering cage diving with Great White Sharks. The two companies offering shark diving in cages are "Incredible Adventures" and "Great White Adventures". Incredible Adventures has been running shark trips very successfully for many years. In 2010, they submitted a study to NOAA, which estimated that the total direct and indirect economic impact was close to 2,000,000 USD for the local economy. However in the last 2 years numbers have dropped greatly and in 2016 a mere 2 trips of 18 possible trips went 
out during the season due to poor oceanic conditions. Only one other shark tourism operates in California; a small number of operators that offer Blue Shark and Mako Shark encounter out of San Diego.

In Alaska a somewhat more recent form of shark tourism has taken hold. In the months of June, July, and August, divers and snorkelers travel to a remote area in the Prince William Sound in the hopes of having encounters with Salmon Sharks. These sharks are one of the fastest sharks in the world and resemble Great White Sharks, to which they are closely related. During weeklong trips, people can meet these fast swimming sharks. The snorkelers remain beside the vessel and fish bits are thrown into the water to attract sharks. Notoriously shy, these sharks often do not linger and only a small number of people have had a close and extended encounter with them. However, this does not stop many enthusiasts from spending 2500 USD for a weeklong trip. This price excludes the flight to and from Alaska and other indirect spending. Between a lodge and a boat operator an estimated 100,000 USD in direct revenue can be attributed to shark trips. In addition, travel to and from the lodge combined with local spending further increase the economic impact of this nonconsumptive shark industry.

\subsubsection{Salmon Sharks}

Ravencroft lodge, situated close to Port Fidalgo in Alaska, is run by Boone and Gina Hodgin. They offer ecotourism trips that include encounters with Salmon Sharks. In addition, they run a citizen science project that focuses on abundance estimation and identification of these sharks when they are in the area. Gina Hodgin is a biologist, and since the lodge is right in one of the prime areas where the sharks traditionally congregate, she has worked on various shark projects. Over the years, she has compiled a photo library to help identify individual sharks that migrate to the area. Additionally the lodge uses images of sharks taken by their ecotourist clientele to populate a database of the Salmon Shark population around Port Fidalgo. These images are used to determine which individuals are in the area during a given time period, and whether the same sharks make the migration to this part of Alaska year after year. One of the larger canyon walls used by Salmon Sharks to ambush prey lies within sight of the lodge, thus allowing a unique opportunity to regularly study and learn from numerous interactions at close range. Although Salmon Shark encounters are seasonal, they form an important part of the lodge's revenue and also support other local businesses. On an annual basis, they offer six trips with an average of six divers who come specifically to see Salmon Sharks (Fig. 2). 


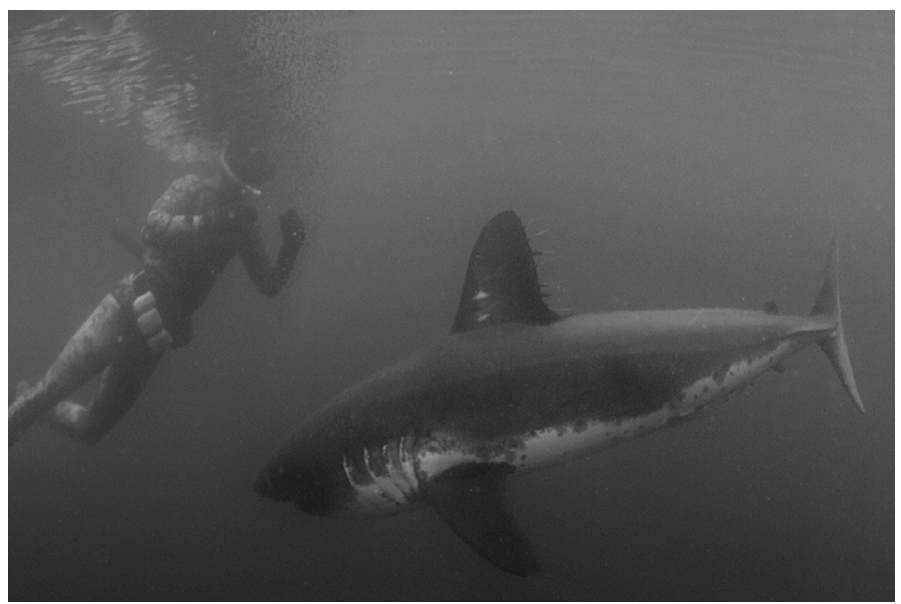

Fig. 2 Snorkler with salmon shark. Photo Credit: Boone Hodgin.

Salmon Sharks have been at the heart of a conflict between consumptive fisheries and ecotourism coupled with citizen science. From 2001 to 2011 a variety of fishing charters offered recreational shark fishing trips. These fishing charters operated out of Valdez, Wittier, Homer, Seward, and Cordova and were in direct conflict with the shark ecotourism in the area. Although charter captains claimed that most of the sharks were tagged and released, the majority of pictures on their websites showed landed and killed sharks (source: Orion charters). In 2006 the largest number of retained Salmon Sharks, 246, was reported by charter operators to the ADFG. The reported catches of Salmon Sharks had been rising steadily since 2003. It grew from 86 retained sharks in 2003 to 207 sharks in 2007, with the peak at 246 retained sharks in 2006. These numbers merely reflected the reported numbers from recreational fishing charter logbooks and did not account for sharks landed by unguided fishermen.

In 2008, a singular image was published on the Fish Alaska Magazine's website that showcased a kayak fisherman with a dead Salmon Shark draped across his kayak. This image was the catalyst to the large-scale shark harvesting that continued on an unprecedented scale. Ravencroft lodge, along with numerous other lodges and charters, was inundated with phone calls from potential fishing clients who wanted to catch a shark. It was big business for fishing companies. Charters and lodges from Valdez, Cordova, Seward, Whittier, Homer, parts of Southeast Alaska, and British Columbia were quickly changing from salmon and Pacific Halibut (Hippoglossus stenolepis) fishing to strictly shark fishing. Over the course of 2 years, charters 
could catch six sharks a day over a 3-month fishing season. An estimated total of 340 sharks were caught from 2007 to 2009 (source: ADFG). Revenue impacts were estimated to be 3000-4000 USD per charter per fishing day deriving from the price that was paid by recreational fishermen. However, the ADFG reported that there was no rigorous editing of the logbook data and the total numbers might well be higher.

Despite being in the ecotourism market, Ravencroft lodge joined this recreational fishery "Bonanza", allowing clients to catch and harvest sharks. During that time catching a Salmon Shark was extremely easy but when clients refused to utilize the shark meat, Ravencroft lodge opted out of this fishing experience and at the time had only harvested a handful of sharks. As this intense fishery continued and reports came in of charter operators continually bringing in their limit of six sharks per day, every day, Ravencroft lodge decided to raise the alarm about the large amount of sharks being taken in a short amount of time. They started to communicate with ADFG to let them know that they were in a unique position to watch the harvest and monitor its impact on the exact spot the sharks migrated to. However, state regulators did not believe the population was declining at the time and did not think any action needed to be taken.

In addition to recreational shark fishing, the commercial fishing industry was also adding to impacts upon the population. There has been no directed commercial shark fishery, with the exception of North Pacific Spiny Dogfish, in Alaska since 1997. However, Salmon Sharks are often incidental bycatch of other commercial fisheries, such as the salmon fishery. This impact was seen less often since most commercial fishermen discard bycatch before returning to port. Amy Carrol, a writer and publication specialist with the division of commercial fisheries at the ADFG, summed up the attitude with the following quote, "Salmon Sharks are often brought up in commercial salmon fisheries as bycatch and are considered a nuisance and thus discarded" (Alaska Fish and Wildlife News, 2007). Thus it is hard to assess the exact impact of bycatch, but the commercial interest is high in the area due to the huge volume of salmon runs that migrate to the region. Commercial fisherman will often refer to these sharks as a pest that destroys nets and gear if accidentally caught. Commercial fishing does not allow them to kill these sharks; however, dead sharks are found regularly floating in areas where commercial fishing occurs (B. Hodgin, personal communication).

According to a recent Stock Assessment and Fishery Evaluation report of the Gulf of Alaska by the North Pacific Fishery Management Council, the 
incidental catch of Salmon Sharks in the Gulf of Alaska was estimated to be 141 tons in 2007. Although this data does not include the incidental catch from the fishery in Prince William Sound (area 649), it does indicate a spike year for Salmon Sharks. As the estimated mortality rate for this report is set at $100 \%$, it can explain the large impact that this may have had for the Salmon Shark ecotourism operator, especially combined with the recreational retention of this shark species in the same period. The combined impact of the recreational fishery, commercial bycatch, and the speed with which the drop in the shark population happened created rapid and drastic changes for the regional Salmon Shark population. In places where previously hundreds of sharks were seen, few were seen.

By 2009, the height of the recreational shark fishery was over and charter operators and lodges changed back to salmon and halibut fishing. Clients were becoming increasingly upset spending large amounts of money on trips to a remote part of Prince William Sound in search of sharks, only to find none.

For Ravencroft Lodge the drop in the number of sharks had a big impact on their revenue stream and, in 2009 and 2010, they did not see the sharks return. In 2011 they saw only a handful of sharks. Each year after that, a few more sharks would return, slowly increasing the number of sightings. In 2016, more than 30 sharks were seen and the Lodge restarted the photographic catalogue of known sharks returning to the area. However, this is still a very low number compared to hundreds of sharks that used to inhabit this area.

According to the IUCN, Salmon Sharks are labelled as Least Concerned. Specifically, "The Salmon Shark occurs in the eastern and western North Pacific and its population appears to be stable and at relatively high levels of abundance. Currently there is no directed fishery in the NEP, apart from a small sport fishery for the species in Alaska. Bycatch in the Northeast and Eastern Central Pacific appears to be at low levels and is not increasing at this point-in-time".

A research paper by Hulbert et al. (2005) stated that there was an abundant population of Salmon Sharks in the NEP from 1998 to 2001. Most of the historical research conducted on Salmon Sharks was taken before 2000-2007, during the peak of a healthy shark population. A recent report of the North Pacific Fishery Management Council has adjusted the data with updated estimation methods for biomass and catch numbers. However the perception amongst ecotourism operators remains that population rates are heavily skewed with old data. 
Recreational fishing interest still exists in this area and the shark population is still believed to be recovering, but it is a fragile recovery that could be jeopardized easily if one or two charter boats, over a few days, decided to take the old practice of fishing for these sharks. With that, shark ecotourism could be negatively impacted once more. Ravencroft lodge, still the only commercial operator that promotes nonconsumptive shark tourism for Salmon Sharks, approached the city of Valdez to help make the case for the value of a live returning shark vs the one-time dollar value of a harvested shark. However, they quickly found out that they merely generated a renewed interest in catching and stringing up a shark for a photo opportunity.

It is likely that the scale and value of recreational fishing for these sharks could outperform the current ecotourism value and threaten conservation initiatives aimed at helping the Salmon Shark population recover. On one hand the low number of sharks will most likely prevent any large-scale recreational fishing. However, should the population rebound to the pre2001 numbers, a risk exists that history may repeat itself. It is encouraging that the global dive industry is increasingly interested in this shark species and thus underlines the case for nonconsumptive shark ecotourism.

\subsubsection{Basking Sharks}

With the global demise of shark populations and the economic impact of shark ecotourism, it is natural to investigate the negative impacts of human activities, and the lack of conservation measures and regulations in some cases, on shark ecotourism by simply preventing the opportunity for people to view sharks. One of the clearest examples of this in the NEP was the eradication of Basking Sharks in British Columbia and the inland waters of Washington State (aka, Puget Sound).

Basking Sharks (Fig. 3) have historically been present, and at times even common, in the NEP. These gentle sharks would turn up close to the coast in the summer months to feed primarily on plankton. Despite their completely inoffensive nature the press, spurred on by the fishing industry and ill-informed general public, portrayed these sharks as "salmon-killing monsters" (Victoria colonist, September 9, 1955). Various other species were also seen as competitors with the salmon fisheries at this time, with seals blown up with mines and a 0.50 calibre machine gun mounted at Seymour Narrows to shoot at Orcas. Although it was actually never fired, the intent was there, and it speaks volumes regarding the mentality that prevailed in these times and the perceived threat that some marine creatures represented to commercial fisheries in Canada. In the 1950s and the early 1960s, the 


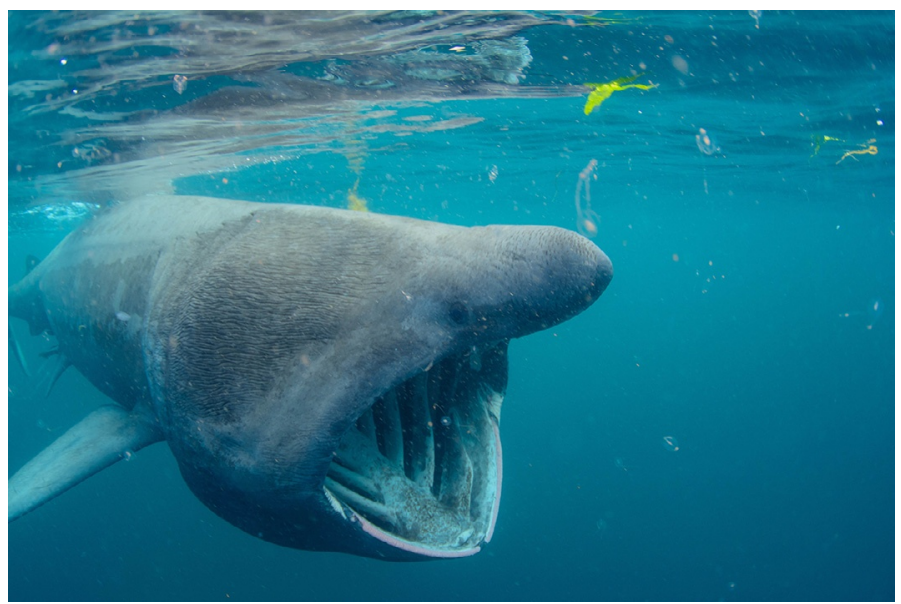

Fig. 3 Basking Shark. Photo Credit: (C) Shane Wasik Basking Sharks Scotland.

Basking Shark population in BC was nearly eradicated due to a conflict between sockeye salmon gill net fishermen and the sharks' surface feeding behaviour for plankton. Basking Sharks feeding at the surface sometimes became entangled in the salmon gill nets causing damage to the gear. The solution that was implemented consisted of a giant knife mounted on the "Comox Post", a patrol vessel of the then Federal Department of Fisheries (currently the Department of Fisheries and Oceans and Coast Guard or DFOCG). The vessel would locate a shark on the surface and ram the mounted knife into the shark, thus killing it. At the height of the eradication activities up to 34 sharks were killed in a single day (Vancouver Sun, April 23, 1956).

Currently the DFOCG has a totally different interest in Basking Sharks. Efforts to establish whether there are still some sharks present in BC waters have resulted in a call to all boaters, divers, and other people in and on the water to report any sighting of these sharks. Between 2008 and 2016, 28 reliable sightings have been reported but only 6 have been confirmed (http:// www.dfo-mpo.gc.ca/species-especes/profiles-profils/basking-pelerin-eng. html). It is unclear how many different individuals were sighted because some reports came from nearby locations in a narrow temporal window, and solitary sharks moving along the coastline could have been sighted at various locations during their roving; thus one shark could have been counted as many. The NEP population of Basking Shark was assessed as "endangered" in 2007 by the Committee on the Status of Endangered Wildlife in Canada (COSEWIC). In February 2010 the population was listed as 
"endangered" under Canada's Species at Risk Act (SARA), giving it legal protection. However, it is doubtful that even if the NEP population recovered that an ecotourism industry would develop. Current encounter guidelines do not allow swimming, snorkelling, or diving with the sharks, which is seen as harassment. Only if the population rebounded to the level where the species would be delisted from SARA, would an ecotourism around Basking Sharks develop. In addition, this is not likely to occur any time soon given the slow reproductive rate of this shark with full recovery to preeradication abundance levels likely taking decades.

In other parts of the world where Basking Sharks occur and were not targeted for elimination, there is clear evidence that this species represents a significant opportunity for ecotourism. For example, on the Isle of Man and in Scotland (Isle of Oban) the local Basking Shark populations had similar conflicts with herring nets and lobster pots. Small-scale and sporadicdirected fisheries for this shark by Norwegian vessels were thought to be too little to inflict substantial impacts on the local population. Later it was recognized that these sharks not only represented an important part of the marine ecosystem but also had an economic value. Today Basking Sharks are an important attraction for tourists and many visitors pay up to 1200 USD per person for a week of snorkelling with these iconic animals. To get a glimpse at the annual revenue stream this shark tourism generates, we look at the Isle of Man. In 2009, 23\% of visitors to the island stated that they came specifically to see Basking Sharks and 69\% stated that their decision to come was influenced by the option to see these sharks (Clarke, 2009). According to the government "Isle of Man Tourism Visitor Economy Strategy" report of 2013, the number of tourists arriving was around 280,000 with a high number of visitors having been to the Isle of Man previously. If $23 \%$ of visitors came specifically for the sharks with an average visitor spending of $£ 321$ with direct economic spending to view sharks totalling approximately $£ 21,380,800$ (41,334,000 USD based on the 2009 exchange rate). In 2009 there were a total of 835 reported Basking Shark sightings (government of the Isle of Man 2009). After 2011 shark tourism revenue was negatively impacted as the number of sharks sightings dropped. In 2015, only 115 shark sightings were reported and in 2016 this further declined to 46 reported sightings (Manx Marine Environmental Assessment 2016). This decline underlines the importance that a healthy and thriving shark population can have on the tourism industry and the local economy. In Scotland on the Isle of Oban the annual value of Basking Sharks for the island's economy is estimated to be more than 250,000 USD generated by 
the approximately 500 visitors arriving to see the sharks. This value excludes any indirect revenue for accommodation, food, and ferries to and from the mainland related to this tourism. These sharks have also been seen regularly around Devon in 2015 and 2016, with unknown economic impact (http:// www.sharktrust.org; 2016).

During the hey days of the Basking Shark "craze" in the Isle of Man and Scotland the importance of the economic impact resulted in a "Code of conduct" that the kayak, dive, boat, and snorkel operators adhered to. This code aimed to minimize anthropogenic disturbance to the shark and was a direct conservation result associated with the economic value of shark ecotourism. Furthermore, widespread awareness of the potential hazards of human activities to these sharks helps conservation programs with no formal entanglement of sharks in any type of fishing gear reported in the United Kingdom from 2003 to 2013 (Hanley et al., 2013).

Given the small sample of the two global hot spots for Basking Sharks ecotourism and the potential a similar tourism opportunity this would have represented for the NEP, specifically $\mathrm{BC}$, one can only regret the loss of these iconic sharks and the potential economic benefit of ecotourism associated with them.

\subsubsection{Sixgill Sharks}

Close encounters with large pelagic animals like sharks, manta rays, sailfish, pinnipeds, and cetaceans, in a tamed and globalized world, find some people prepared to pay a substantial part of their annual income for a rare, perhaps "once in a lifetime", experience. In 1994 as this trend was just starting to unfold, the economic benefits of ecotourism were documented by bringing divers face to face with a poorly known, giant, cold water shark, the Bluntnose Sixgill Shark in the NEP waters of Canada (Harvey-Clark, 1994). At this time at least 10 SCUBA diving tourism operations on the $\mathrm{BC}$ coastline were deriving a portion of their gross income specifically from charters to dive with and experience these rare sharks. The Sixgill Shark is a large-bodied, deepwater shark, reaching $5 \mathrm{~m}$ in length and over $600 \mathrm{~kg}$ in weight, that exhibits a worldwide distribution and in some regions ventures into shallow water where it may be encountered by divers. This is particularly true in the summer months in the Pacific Northwest region of North America. Listed as near threatened by the IUCN (Cook and Compagno, 2005), Sixgill Sharks have been anecdotally reported by SCUBA divers since at least 1972 in this region (Harvey-Clark, 1994) as an occasionally sighted, seasonally species in several locations in BC, specifically Hornby Island in the 
Strait of Georgia, Gold River, and Barkley Sound, as well as in Puget Sound, Washington. From the late spring through the fall, large specimens of Sixgill Sharks were documented at these locations in the 1990s and the early 2000s.

An ecotourism survey was conducted in 1993-1994 within the province of BC to determine to what extent Sixgill Sharks were critical to attracting and retaining diving tourism, and to establish the dollar value to dive charters associated with shark ecotourism (Harvey-Clark, 1994). Ten dive charter operations were supplied with a survey form, with two follow-up phone calls to review the survey form, and seven operations agreed to participate in the survey. The results were surprising, documenting an average of 26,050 Canadian dollars per operation in annual gross revenue specifically ascribable to shark charters, or more than half the average total dive charter revenue per operation. This represented 1150 diver charter days. Fifty-three percent of all customers were from out of province and 66\% were repeat customers, indicating a high degree of sustainability for this type of charter operation. The seven businesses employed 15 persons full time and a further 14 part time, and each spent an average of 81,250 Canadian dollars per annum in operating expenses.

At around the same time, in the 1990s, the salmon troller fishery industry in $\mathrm{BC}$ was experiencing increasing pressure in terms of diminishing salmon catches and tighter restrictions on opening and closing of seasons. Troller captains were looking for other sources of income and at "underutilized species". In 1991 a consortium of three troller operations, with assistance from the BC provincial government, initiated a pelagic Blue Shark longline fishing operation based in Tofino, $\mathrm{BC}$, as an experimental fishery. However, the severe sea/weather conditions and vessel size limitations in the offshore environment led the fishermen to attempt to fish the deep, weatherprotected fjords of the West coast of Vancouver Island instead. Here they quickly learned to capture Sixgill Sharks, and the subsidized Blue Shark fishery morphed into a subsidized Sixgill Shark fishery, proceeding in the absence of any normative data on the target species to support sustainability. It was apparent to some biologists however that the large size, rarity, and slow growth rate of this species (Ebert, 1986) likely precluded a sustainable fisheries model. An attempt to market Sixgill Shark as "snow shark" failed due to a combination of poor palatability and marketability of shark meat, and concerns about the mercury content in this long-lived species. While, to date, a verified reliable and accurate method for aging Sixgill Sharks remains elusive (see Matta et al., 2017), it appears that this species is slow growing and lives for many decades, and as a piscivorous species is high 
in mercury content. From 1991 to 1994, the cost of production in the experimental fishery consistently exceeded the market price for Sixgill Shark, and eventually government subsidies for the fishery were exhausted. Following the publication of the Sixgill ecotourism survey in 1994 the lead author directly lobbied DFOCG, which licensed the fishery, to stop commercial fishing when research results made it clear that there was a strong economic argument to protect the sharks and focus on ecotourism. In short order the fishery collapsed in the absence of a market for the product and public concerns regarding sustainability.

The aftermath of the fishery is difficult to quantify, but 22 years later Sixgill Sharks have not returned in their former numbers to BC waters at sites where they had been seen for the previous 30 years by divers. Observations decreased at all known and regularly dived Sixgill Shark locations, although this was never scientifically quantified and remains an incidental observation. Studies at Hornby Island (Dunbrack and Zielinski, 2005) using underwater video recording stations at a site had noted a high incidence of anthropogenic injury due to fishing gear in an area where sixgills had once been regularly observed. The same authors have since reported a steep decline in the number of sightings after 2004 although the targeted sixgill fishery was not active in this area ( $\mathrm{R}$. Zielinski, personal communication, 2016). The DFOCG website on species at risk acknowledges a $90 \%$ decline in the observations of Sixgill Sharks in the Strait of Georgia many years following the fishery: "Encounter rates with immature Bluntnose Sixgill Sharks at a shallow site in the Strait of Georgia have decreased by more than 90\% over the last five years based on video surveillance and anecdotal diving records. It is unlikely the decline monitored at this site is related to bycatch mortality, but may be a distributional change related to major changes in environmental conditions such as increased water temperatures in the Strait" (DFOCG, 2016).

This decline could also be explained in part by changes in Sixgill Shark year class structure moving into offshore areas, as was seen in Puget Sound, Washington, in the years from 2004 to 2011 (Williams et al., 2010). The decline also coincided with a general decrease in SCUBA diving ecotourism and the disappearance of many operations, so diver unit effort to view Sixgill Sharks may have been a factor in the decreased number of diver observations. The ultimate positive outcome of the publication of the Sixgill Shark ecotourism report in the proceedings of the Second International Symposium on Protected Areas (SAMPAA; Harvey-Clark, 1994), and direct lobbying of DFOCG, was the discontinuation of licences to experimentally fish 
Sixgill Sharks, which remains in effect. In 2011, additional regulations were passed to prevent the targeting of this species in sports fisheries on Canada's west coast and harvesting of Sixgill Sharks has been prohibited in Puget Sound waters since 2005 .

\subsection{Citizen Science}

Citizen science is, in principle, nothing new. In fact, many of the early discoveries in the 1800s where done by the wealthy gentry who had the time and money to travel, do experiments, and make observations. Most of them had no formal scientific training. As technology and industrialization advanced, science became a profession and schooling to become a scientist became structured. However, the basic principles of scientific observations, experiments, and reporting are universal and easily acquired by those interested in them. Especially with Massive Open Online Courses (MOOC) on the internet held by many universities around the world, more people now have access to learning these principles.

So what drives citizen science and, specifically, shark-related projects? As the general public has become more aware of environmental issues, like climate change, and the effects of such factors on their daily life and surroundings, many people want to actively contribute to research and take meaningful action to offset these impacts. Within the diving community, sharks have now become a desired object of photography and a reason to travel. Many species of enigmatic sharks such as the Tiger Shark (Galeocerdo cuvier), Great White Shark, and Lemon Shark (Negaprion brevirostris) are well known to the diving community and shark tourism associated with these species creates sustainable economic benefits for local economies. Some tourism operators make the identification of individual sharks and rays part of the experience and share their database of observations with the scientific community, e.g., citizen science. At the same time, they try to educate divers on the shark species, their importance, and the threats they face.

As previously mentioned, many shark species in the NEP are harder to find and less studied. This has led to a data gap in both the scientific community and with resource management authorities. As many of the shark species either live offshore or in deep waters the costs of doing consistent in-water monitoring are high, despite advanced technologies like datalogging tags, remotely operated vehicles, and small submersibles. The mere ratio between the number of sharks and the vast territory in which they 
might be observed makes many of these attempts very costly with a low encounter rate and, thus, a generally low rate of success.

The data gap combined with the potentially high costs of field research has led, in some cases, to interested members of the diving community starting their own observation projects. These projects are done in specific local areas where active divers encounter sharks on a regular or a seasonal basis, and since they combine the fun of diving with the underwater observations the actual costs are very low. With the advances of rebreathers, mixed gasses, and digital imagery now available at relatively low cost to a wider public, the opportunities and capabilities of citizen science have increased substantially. The scientific community has been somewhat reluctant to accept these observations, and in many cases, they are seen as anecdotal information rather than systematically gathered data sets, but some citizen science projects have a sound basis of data logging and observation methods.

In Canada the DFOCG has adopted a pure citizen-based shark-sighting network in the hopes that they will obtain sighting data offered by those who are working and recreating in and on the water. However, sharing this data with the public is still not an automated option and although information can be requested, it is not a two-way information exchange similar to other citizen-based data networks like Reef Environmental Education Foundation (REEF.org). This raises another interesting facet of citizen science; as raw data is often summarized, interpreted, or not available to citizens, especially in situations where far-reaching decisions are taken on environmental or conservation issues, people feel that they do not have the opportunity to access and evaluate the data that supports these decisions. In these cases, good citizen science can offer data that can help to better understand the rationale behind the proposals. An example of a proposal that requested public input is development of a management plan for Tope Shark (Galeorhinus galeus) and Sixgill Sharks. Between May and June 2011 stakeholders and other interested parties were invited to give feedback and input on the proposed management plan. Rendezvous Dive Adventures was one of the parties that responded and the input provided was solely based on the results and experience of their citizen science project. Although the final "Code of conduct" that resulted is mainly directed towards sharks entangled or caught in fishing gear, some of the elements can also be used by divers. This code of conduct is a recommendation and does not reflect an enforceable act. 


\subsection{Case Studies}

\subsubsection{Broadnose Sevengill Sharks (Notorynchus cepedianus)}

Traditionally, academic science has used undergraduate and graduate students to collect data, but community or citizen science has revolutionized the process by which large amounts of data can be collected accurately by large numbers of nonscientists under the training and mentorship of scientists. Although there has been some discussion in the scientific community about whether the data collected by citizen scientists is as scientifically valid as data collected by traditional methods (Cohn, 2008). In the field of marine science, citizen science has been used to monitor the impact of invasive marine species in specific communities (Delaney et al., 2007). Several marine nonprofit organizations, including REEF.org and Reef Check California, have successfully collected and submitted data using citizen-science methods for use in coastal management and marine biology studies. These data sets represent both a scientific value and a monetary value.

Comparatively fewer citizen science studies have been done on sharks. One encouraging study has shown that data collected by citizen science divers on reef sharks can be on par with that collected by automated methods, such as acoustic telemetry (Vianna et al., 2014). Vianna et al. (2014) is quoted in Science Daily as saying, "Our study shows that with a little bit of training and a good sampling design, recreational divers collect very useful data that can be used to monitor shark populations over long periods of time and across large spatial areas. Such programs have relatively small costs when compared with other methods currently used" (Science Daily, April 23, 2014, https://www.sciencedaily.com/releases/2014/04/ 140423221414.htm).

The San Diego-based nonprofit Ocean Sanctuaries (oceansanctuaries. org) was founded in 2014 to create and provide support for marine citizen science projects. The Sevengill Shark Identification Project was one of its first citizen science projects, begun in 2010 in response to anecdotal evidence that divers were seeing increasing numbers of Sevengill Sharks off the coast of San Diego. This made the species an ideal candidate for a long-term (5-10 year) population study. During this period, Ocean Sanctuaries partnered with information architect Jason Holmberg, who had helped design the original pattern recognition algorithm that had been used to identify Whale Sharks, Rhincodon typus (Arzoumanian et al., 2005). Arzoumanian later used this and another algorithm to create Wildbook (http://www. 
wildbook.org), an open source software framework to support collaborative mark-recapture, molecular ecology, and social ecology studies, especially where citizen science data needs to be incorporated and managed.

Divers who encounter a Sevengill Shark during a dive in California can take photographs of the lateral view of the head and gill area without compromising their safety (Fig. 4). After the dive they can upload their photographs to the Wildbook database at Sevengill Shark Sightings. This study has now expanded to Cape Town, South Africa, as part of a citizen science partnership between Ocean Sanctuaries and the Two Oceans Aquarium (http://www.aquarium.co.za/blog/entry/citizen-science-global-sevengillshark-identification-project) in Cape Town, as part of an effort to include citizen science photographic documentation from False Bay, South Africa, another area where this species is commonly seen.

Contained within Wildbook are two pattern recognition algorithms, which scan submitted photographs and analyse the black freckling pattern seen around the eyes and gill area of this species facilitating individual recognition. In this way, photographs submitted over time in a single location can determine if, and which, sharks are returning to the location from year to year (Bear, 2016). High definition photographic data collection methods are replacing the older diver identification method, because they are more accurate for species identification. The Sevengill Project uses high definition photography, which provides much more detail about encounters with this species.

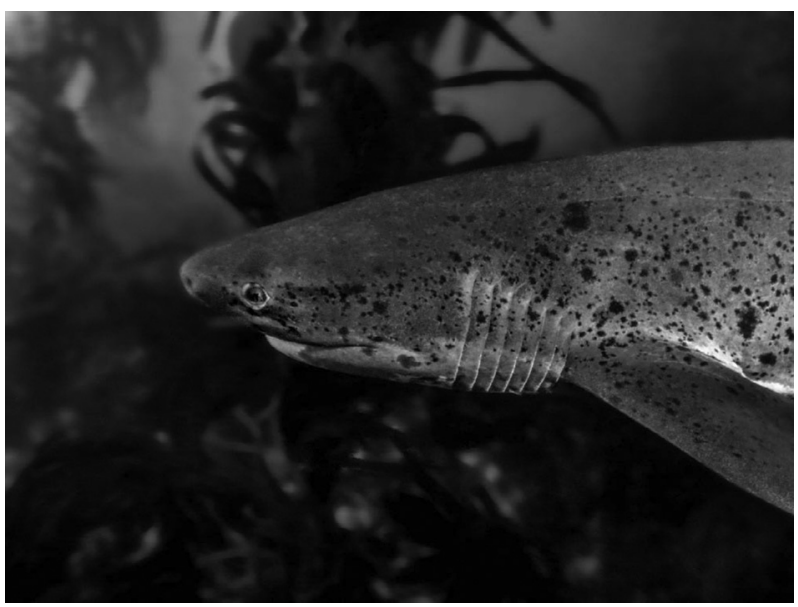

Fig. 4 Sevengill Shark. 


\subsubsection{Sixgill Shark}

A more recent hybrid between a citizen science project and ecotourism has been running officially since 2010 in Barkley Sound on the west coast of Vancouver Island. The project is called "shark survey week" hosted by Rendezvous Dive Adventures and typically runs in the last 2 weeks of August. Rendezvous Dive Adventures is located in Rainy Bay, Vancouver Island, situated at the mouth of Barkley Sound on the west coast of central Vancouver Island. The survey is run in conjunction with Dr Chris Harvey Clark and records not only Sixgill Shark size but also sex and abundance. Observations are also made for Spotted Ratfish, Hydrolagus colliei, another chondrichthyan seen in the area. This work carries forward a Sixgill Shark observation logging program initiated by diving biologist/naturalist and filmmaker Neil MacDaniel in the 1980 s and represents a near continuous data set spanning almost three decades.

Participation in Shark Survey Week is offered to visiting client divers in late summer in conjunction with lectures and films on elasmobranch biology delivered by visiting scientists. During the survey period participants dive sites that are known to have higher numbers of Sixgill Shark observations, and record the number of target species observed at specific sites. Records of shark observations per unit effort and specific identifying records for shark and ratfish sightings (video, still images, size, sex, number) are maintained by Rendezvous staff with the intention of characterizing changes over time. One hypothesis being investigated is that the occurrence of Sixgill Sharks in shallow waters may coincide with summer inshore migration of certain prey species, specifically Spotted Ratfish. Shark Survey Week is an outstanding example of citizen science using dedicated ecotourism clients as data gatherers, in an "edutainment" model that combines serious science with recreation and learning. Many participants return year after year. The data collection part of the project is mainly done through SCUBA diving observations, but occasionally remote cameras have been used during hours where no divers were in the water. For the remote camera used in 2013, the reef in front of the lodge was used facing a baited cage. No divers were in the water and recording took place between 11:00 pm and 07:00 am.

One positive consequence of the citizen science operation at Rendezvous Dive Adventures is the provision of a regular survey effort with a critical mass of observers consistently checking a remote and difficult to reach part of Vancouver Island's west coast waters, documenting a sparsely abundant species. To duplicate this effort would be cost prohibited for most grant-funded researchers without the generous subsidy in boat, diver, and 
infrastructure services supported by the Rendezvous operation, as well as leveraging the operators extensive local knowledge. In turn, this effort has resulted in some unique observations; a number of rare early-stage juvenile Sixgill Sharks have been observed. Another tangible outcome of the project has been development of a survey form that has been adopted by CDFCG, which can be downloaded and filled out by anyone seeing a Sixgill Shark underwater or washed up on shore (http://www.rendezvousdiving. com/wp-content/uploads/2014/12/sharkworksheet.pdf). The form was also adopted by the Vancouver Aquarium, which then started a similar sighting database. This underlines an increasing trend in shark awareness and interest for little known species of sharks.

The number of sightings of Sixgill Sharks has varied over the years (Fig. 5). During peak years as many as 17 sightings of sharks are made and in some years there are zero sightings. As a trend, it seems that seven to eight sightings are a rough average between 2004 and 2015. In 2014 there were eight sightings; however, the same shark was seen five times based on a distinct notch in the dorsal fin that was documented in videos and photographs. It was observed in a near identical spot on the same dive site. Diving observations of sixgills over the past 35 years have consisted almost

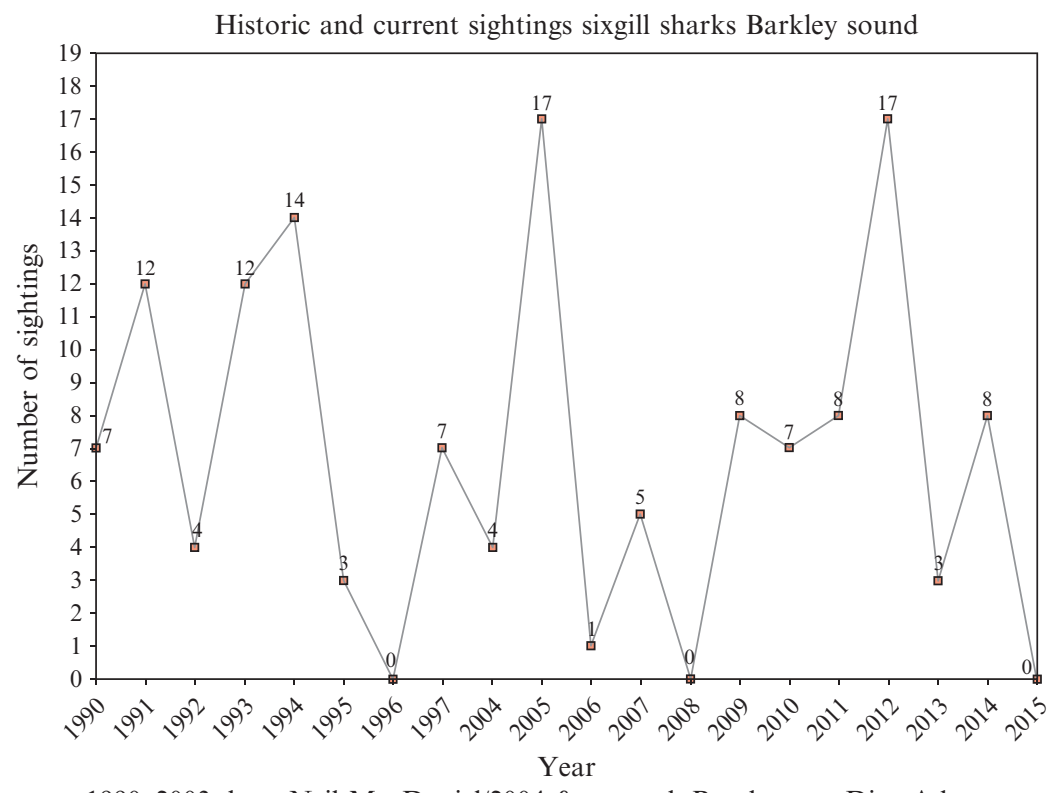

1990-2003 data: Neil MacDaniel/2004 \& onward: Rendezvous Dive Adventures

Fig. 5 Sixgill sightings during Rendezvous Dive Adventures shark survey week. 
exclusively of larger animals in the $2-4 \mathrm{~m}$ range, whereas young, $1-1.5 \mathrm{~m}$ long juveniles of this species are virtually unknown in diving observations. The largest shark observed was a female with a total length estimated at $4.2 \mathrm{~m}$, and the smallest shark observed was $0.8 \mathrm{~m}$ with an unidentified sex. Rendezvous divers have observed juvenile sixgills in the $1 \mathrm{~m}$ range resting on the bottom, not swimming, for extended periods, a behaviour not previously seen in this species (Fig. 6). Juveniles have exhibited this behaviour when large adult sharks are nearby, a notable feature in this cannibalistic species, which may represent defensive prey crypsis. Such field observations documented via underwater still and video cameras are a significant contribution to the knowledge of the biology and behaviour of this poorly known species (Figs 7-9).

During a number of years it seemed that there was a direct relationship between the abundance of Spotted Ratfish and Sixgill Sharks. However in 2013 and subsequent years it became clear that the abundance of Spotted Ratfish was stable, while the abundance of Sixgill Sharks had dropped. This seems to refute the idea that there is a direct relationship between the abundance of the two species. Another hypothesis suggesting a correlation between the size of local salmon runs and presence of Sixgill Sharks has also been disproved. The sighting data that was obtained has been shared with the Seattle Aquarium, the Vancouver Aquarium, and the DFOCG. In the DFOCG database there are 37 entries of sightings of Sixgill Sharks since 2008, the majority of which came from the Rendezvous Dive Adventures shark survey week, underlining the role that citizen science can play.

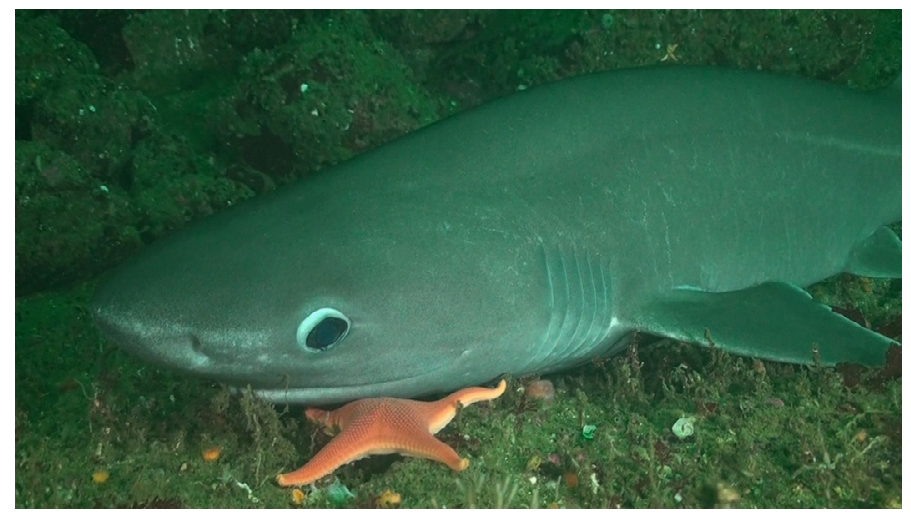

Fig. 6 Juvenile Bluntnose Sixgill Shark. Photo Credit: Peter Mieras/Subvision Productions. 


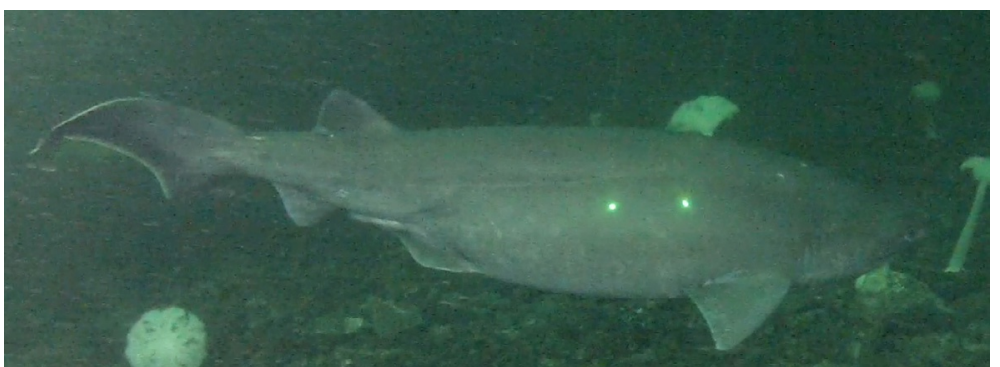

Fig. 7 Bluntnose Sixgill Shark. Photo Credit: Peter Mieras/Subvision Productions.

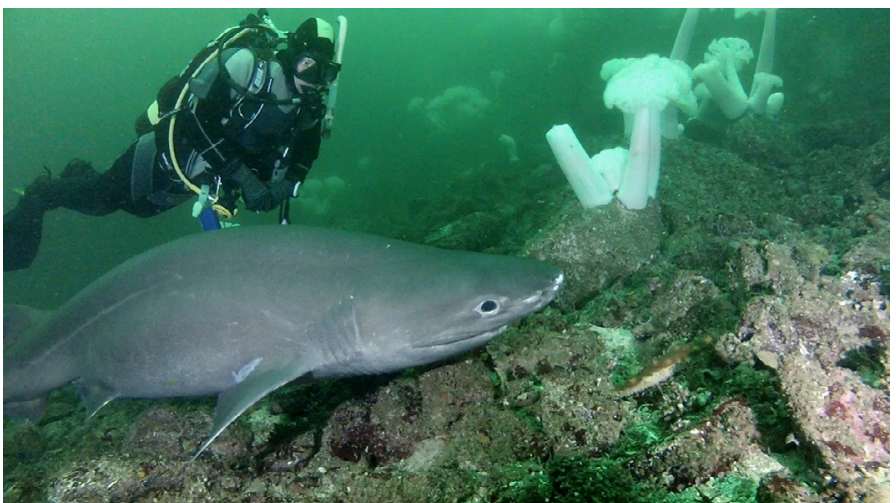

Fig. 8 Diver with Bluntnose Sixgill Shark. Photo Credit: Peter Mieras/Subvision Productions.

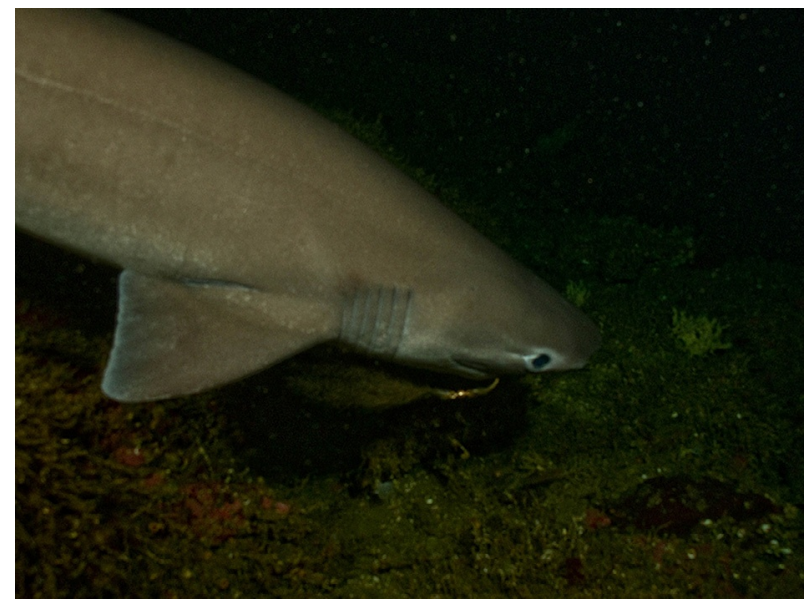

Fig. 9 Bluntnose Sixgill Shark. Photo Credit: Katherine A. Johnson. http://www. watermarkimages.ca. 
The resulting increased awareness has also led to a number of interesting actions by citizens and authorities. In February 2011 workers in the Port Alberni Inlet noted a deceased female Sixgill Shark. They took the time and effort to notify the local officers of the DFOCG and towed the shark into the Port Alberni harbour. Hoisted on a trailer it was weighed and gave the researchers from the DFOCG, who came from Nanaimo, a chance to investigate. They took measurements, biopsied samples, and discovered a number of fully developed pups in the uterus of the female. The prompt action of the citizens allowed further information to be collected and helped to gain more knowledge on this species.

Another result from the project that contributes to the conservation of Sixgill Sharks is the numerous education and outreach opportunities Rendezvous owners have been involved with. A number of national and local radio and TV interviews as well as public speaking engagements have led to better understanding and higher level of interest by the general public. A highlight was the panel presentation at the Vancouver Aquarium on sharks of Canada with participation of Dr Chris Harvey-Clark, Dr Shawn Larson, and Peter Mieras (Fig. 10). This was part of a larger exhibition named "The Secret Life of Sharks and Rays" by the Vancouver Aquarium and turned out to be a big success.

The economic impact of Rendezvous Dive Adventures shark week is relatively small on a global scale. The direct revenue from shark survey week is no more than 20,000 Canadian dollars on an annual basis but it does

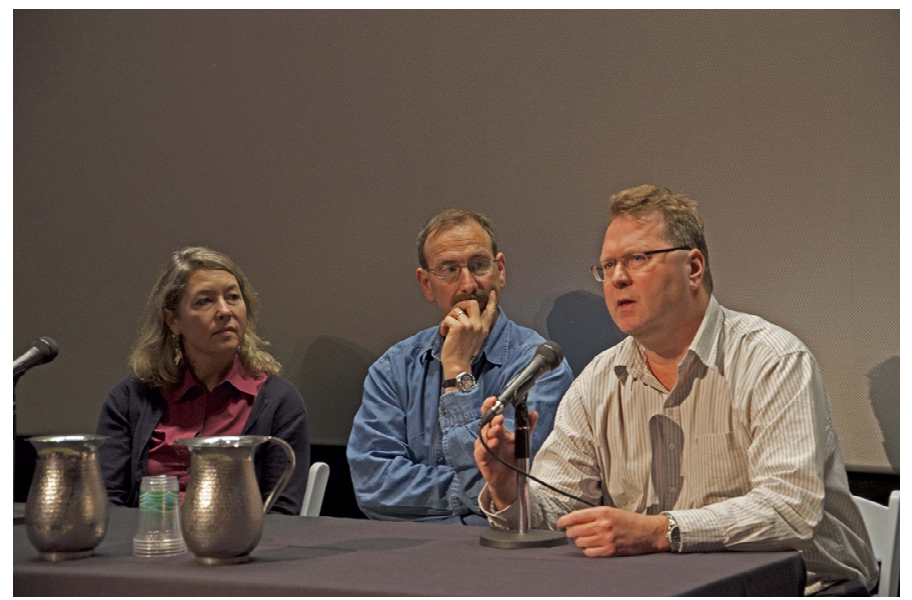

Fig. 10 From left to right: Dr Shawn Larson, Peter Mieras, and Dr Chris Harvey-Clark answering questions from the audience at the Vancouver Aquarium. Photo Credit: Roy Mulder. 
partially support two full time jobs. In addition, the indirect expenditures in the nearby town of Port Alberni at hotels, restaurants, etc., are contributing factors to the total dollar impact of the project.

\section{CONCLUSION}

Compared to the worldwide economic impact of shark ecotourism, shark tourism in the NEP is relatively small. However for a number of local operators and communities, it plays an important economic role. Due to the species of sharks present in the NEP, the chances of seeing them, and the colder water conditions, shark tourism is unlikely to grow to a large scale. Nevertheless, conservation of shark species in the NEP will have a positive economic impact in the region in the long run. Increased awareness due to shark-directed ecotourism had led to a broader support for protection of sharks. There will always be the tension between high value, one-time catch of sharks in some recreational fisheries vs the continued economic contribution of low impact shark sightings. Fisheries management authorities must take into account the value or potential value of nondestructive use of these resources. Even with relatively strict conservation regulations currently in place, it can be argued that for many species it may be too late. The past impacts fisheries have had and the lack of effective conservation measures has led to the reduction or disappearance of certain shark species and their associated shark tourism and underlines the fragility of the industry as a whole, and the dependence on shark populations and their protection.

An exact economic value from shark citizen science in the NEP is almost impossible to calculate. This is due to the very small number of citizen science projects directed towards sharks in the NEP as well as many of the current projects being a hybrid between citizen science and ecotourism. Additionally it is difficult to quantify the savings obtained by data collected by citizen scientists. Scientific institutions use the data, but there is no commercial value attached to this data in any of the studies that uses these data sets. What is clear is that many scientists would not have the funds through grants, donations, or other sources to obtain these data sets on their own. Given this reality it is surprising that in some cases citizen science is still seen as merely anecdotal and in some extreme cases scientists simply dismiss them. However, growing numbers of scientists are taking citizen science data seriously and are willing to integrate citizen science in their research as an additional means of gaining data on poorly understood species of sharks in the NEP. 


\section{REFERENCES}

Alaska Fish and Wildlife News, 2007. http://www.adfg.alaska.gov/index.cfm?adfg= wildlifenews.view_article\&articles_id $=267$.

Arzoumanian, Z., Holmberg, J., Norman, B., 2005. An astronomical pattern-matching algorithm for computer-aided identification of whale sharks Rhincodon typus. J. Appl. Ecol. 42 (6), 999-1011.

Bear, M., 2016. Perspectives in marine citizen science. J. Microbiol. Biol. Educ. 17 (1), 56-59. https://doi.org/10.1128/jmbe.v17i1.1037.

Cisneros-Montemayor, A.M., Barnes, M., Al-Abdulrazzak, D., Navarro-Holm, E., Rashid Sumaila, U., 2013. Global economic value of shark ecotourism: implications for conservation. Oryx 4 (3), 381-388.

Clarke, J., 2009. An assessment of anthropogenic disturbance to the Basking Shark, Cetorhinus maximus, and a valuation of the shark tourism industry on the Isle of Man. M.Sc. Thesis, Marine Environmental Management, University of York.

Cohn, J., 2008. Citizen science: can volunteers do real research? BioScience 58, 192. https:// doi.org/10.1641/B580303.

Cook, S.F., Compagno, L.J.V., 2005. Hexanchus griseus. The IUCN Red List of Threatened Species 2005: e.T10030A3155348. The Department of Fisheries and Ocean and Coast Guard, Canada.

Delaney, D., Sperling, C., Adams, C., Leung, B., 2007. Marine invasive species: validation of citizen science and implications for national monitoring networks. Biol. Invasions 10, 117. https://doi.org/10.1007/s10530-007-9114-0.

DFOCG, 2016. Web site Aquatic Species at Risk. http://www.DFOCG-mpo.gc.ca/ species-especes/profiles-profils/bluntnose_shark-requingriset-eng.html.

Diamond, J., 1999. Guns, Germs, and Steel. W.W. Norton \& Company, Inc., New York City, pp. 43-44

Dunbrack, R., 2008. Abundance trends for Hexanchus griseus (Bluntnose Sixgill Shark) and Hydrolagus colliei (Spotted Ratfish) counted at an underwater observation station in the Strait of Georgia, British Columbia. Can. Field Nat. 121 (2), 124-128.

Dunbrack, R., Zielinski, R., 2005. Body size distribution and frequency of anthropogenic injuries of bluntnose Sixgill Sharks Hexanchus griseus, at Flora Islets, British Columbia. Can. Field Nat. 119 (4), 537-542.

Ebert, D.A., 1986. Biological aspects of the Sixgill shark. Copeia 54, 131-135.

Ehrlich, P.R., Ehrlich, A., 1981. Extinction: The Causes and Consequences of the Disappearance of Species. Random House, New York.

Gallagher, A.J., Hammerschlag, N., 2011. Global shark currency: the distribution frequency and economic value of shark ecotourism. Curr. Issue. Tour. 1, 11-16.

Hanley, L.J., Gell, F.G., Kennington, K., Stone, E., Rowan, E., McEvoy, P., Brew, M., Milne, K., Charter, L., Gallagher, M., Hemsley, K., Duncan, P.F., 2013. Manx Marine Environmental Assessment. Isle of Man Marine Plan. Isle of Man Government, Isle of Man.

Harvey-Clark, C., 1994. In: Shackell, N., JHM, W. (Eds.), Protection of Sixgill sharks. Proceedings of the 2nd International Conference on Science and Management of Protected Areas. Halifax, NS, Canada, SAMPAA Association, Wolfville, NS 1995, pp. 286-289.

Hulbert, L.B., Aires-da-Silva, A.M., Gallucci, V.F., Rice, J.S., 2005. Seasonal foraging movements and migratory patterns of female Lamna ditropis tagged in Prince William Sound, Alaska. J. Fish Biol. 67 (2), 490-509.

Matta, M.E., Tribuzio, C.A., Ebert, D.A., Gburski, C.M., 2017. Age and growth of elasmobranchs and applications to fisheries management and conservation in the Northeast Pacific Ocean. In: Larson, S.E., Lowry, D. (Eds.), Northeast Pacific Shark Biology, Research and Conservation. Part A. Advances in Marine Biology, vol 77. Elsevier, pp. 179-220. 
Murell, D., 2008. 8 Arguments Against a Carbon Tax. Canadian Centre for Policy Studies. www.policystudies.ca.

Myers, R.A., Worm, B., 2003. Rapid worldwide depletion of predatory fish communities. Nature 423, 280-283.

Neff, C., 2014. The jaws effect: how movie narratives are used to influence policy responses to shark bites in Western Australia. Aust. J. Polit. Sci. 2014 (1), 9-11. https://doi.org/ 10.1080/10361146.2014.989385.

Reef Check, 2015. About Reef Check. http://reefcheck.org/about-rc/about-us.

Safina, C., 1998. Song for the Blue Ocean; Encounters Along the Worlds Coasts and Beneath the Seas. Henry Holt and Co., New York City.

Tribuzio, C.A., Hulson, P., Echave, K., Rodgveller, C., 2014. Assessment of the Shark Stock Complex in the Gulf of Alaska. Executive Summary. NOAA. https://www.afsc.noaa. gov/REFM/Docs/2014/GOAshark.pdf.

Vianna, G.M., Meekan, M.G., Bornovski, T.H., Meeuwig, J.J., 2014. Acoustic telemetry validates a citizen science approach for monitoring sharks on coral reefs. PLoS One 9 (4), e95565.

Williams, G.D., Andrews, K.S., Farrer, D.A., Levin, P.S., 2010. Catch rates and biological characteristics of bluntnose sixgill sharks in Puget sound. Trans. Am. Fish. Soc. 139 (1), 108-116. 